\title{
EDUCAÇÃO ANTI-RACISTA: REFLEXÕES E CONTRIBUIÇÕES POSSÍVEIS DO ENSINO DE CIÊNCIAS E DE ALGUNS PENSADORES
}

\section{Anti-racism education: reflections on the possible contribution of science teaching and of some thinkers}

Wilmo Ernesto Francisco Junior ${ }^{1}$

\begin{abstract}
Resumo: Nos dias atuais, muitos autores vêm debatendo a questão do racismo. Entretanto, a questão racial ainda é pouco discutida dentro da comunidade dos pesquisadores de educação em Ciências. Por isso, o presente trabalho tem justamente por objetivo introduzir alguns conceitos importantes envolvidos com o racismo, bem como discutir como o racismo se desenvolveu ao longo dos anos. Além disso, são apresentadas possíveis contribuições do ensino de Ciências e de alguns pensadores da sociologia e da psicologia da educação no combate ao racismo presente na sociedade.
\end{abstract}

Palavras-chave: Racismo. Ensino de Ciências. Educação anti-racista.

\begin{abstract}
Many writers have reflected on the subject of racism. Nevertheless, this theme has not been discussed by science educators. Taking this into account, the aim of the present paper is to introduce some important concepts involved with racism and discuss how it has developed. The paper also presents some possible contributions from science teaching and from sociology and phsycology education to contend with the racism in the society.
\end{abstract}

Keywords: Racism. Science teaching. Anti-racism education.

\footnotetext{
${ }^{1}$ Químico. Doutorando em Química. Docente, Departamento de Química, Universidade Federal de Rondônia (UNIR). Porto Velho, RO. <wilmojr@yahoo.com.br>
} 


\section{Introdução}

Há muito tempo se fala e escuta sobre igualdade social, étnico-racial e direitos iguais a todos. Contudo, a realidade social impregnada, não por acaso, em nossa atual sociedade está distante desse discurso. Em trabalho recente, analisei brevemente a situação atual dos negros como "fruto de um processo de desumanização, devido a uma distorção histórica na qual se instaura a situação-opressora estabelecida pela violência de quem oprime" (FRANCISCO JR., 2007, p. 10). Esta análise, por meio da qual se sublinham duas dimensões, ao mesmo tempo distintas e inter-relacionáveis, se pautou nas idéias de Paulo Freire, as quais muito contribuem para refletir questões de discriminação.

Essas duas dimensões são: (i) a configuração das relações de desigualdades, as quais foram provocadas por meio de uma distorção histórica; (ii) bem como a projeção e disseminação dessas desigualdades no bojo da atual sociedade. Ianni (1997) argumenta que, com a globalização, a discussão das desigualdades e de suas relações étnicas e raciais se intensificou em todo o mundo, configurando implicações sociais, econômicas, políticas e culturais. Todavia, para entendermos melhor o processo, inclusive da distorção histórica, teremos de incursionar mais atrás. Como destaca Ianni:

Esta é uma longa história, começando com os grandes descobrimentos marítimos e desenvolvendo-se através do mercantilismo, colonialismo, imperialismo, transnacionalismo e globalismo. De tal modo que no fim do século XX a África, Oceania, Ásia, Europa e Américas continuam desenhadas no mapa do mundo e no imaginário de todo o mundo como uma multiplicidade de etnias ou raças distribuídas, classificadas ou hierarquizadas de formas muitas vezes extremamente desiguais. (IANNI, 1997, p. 158)

Para se pensar um caso bem próximo, tomemos, como exemplo, o próprio Brasil. Por possuírem um modo de vida extremamente diferente, os povos indígenas foram classificados como arcaicos e sem história - fato este que alimenta a idéia da diferença como sinônimo de inferioridade. A distorção histórica, nesse contexto, é a desigualdade iniciada por esta concepção de diferença como sinônimo de inferioridade, perpetuada através dos anos. $\mathrm{O}$ tráfico negreiro é uma das maiores, senão a maior distorção histórica da humanidade, implicando a vida dos descendentes de escravizados até os dias atuais.

De acordo com Ianni:

Em alguns séculos, todo o mundo foi desenhado e todos os povos classificados: selvagens, bárbaros e civilizados, povos históricos e povos sem história, nações industrializadas e nações agrárias, modernas e arcaicas, desenvolvidas e subdesenvolvidas, centrais e periféricas. (IANNI, 1997, p. 159)

No que tange a todas essas discussões, duas questões, no presente texto, de extrema relevância e de interesse, emergem neste momento. Como se configuraram as relações de 
desigualdades de nossa atual sociedade? O que pode ser feito, tomando por base a escola e o ensino de Ciências, para minimizar essa estratificação? Obviamente, responder a segunda questão é uma tarefa um tanto árdua, mas, ao longo do texto, tentar-se-á discutir e apontar, na medida do possível, tendências as quais possam nos ajudar a compreender e minimizar a discriminação racial. Para tanto, devemos entender como surgiu e se engendrou o racismo na história da humanidade. Deste modo, inicialmente, proponho dar relevo às duas dimensões sublinhadas no início do texto, para, em seguida, discutir, com melhor propriedade, as questões acima levantadas. Ao fim do texto, são discutidas, de forma breve, as contribuições de alguns pensadores da sociologia e da psicologia da educação no que tange à questão do racismo. Além disso, busco com este trabalho introduzir, no seio da comunidade de pesquisa em educação em Ciências, um tema atual, relevante e um tanto abandonado pelo ensino de Ciências.

\section{A velha discussão: existem ou não diferentes raças humanas?!}

Antes que se levante a questão, é importante discernirmos o conceito de raça, uma vez que o abordaremos neste texto. Para Goldberg (2002), o conceito de raça surge na consciência européia, de forma mais explícita, no século XV. Denotando a cor de pele, o termo raça foi empregado, pela primeira vez, como forma de classificar os seres humanos, no ano de 1684, por um físico francês chamado François Bernies (MARTINS, 2005). A primeira expressão de racismo que se conhece foi manifestada na Grécia Antiga por Aristóteles, ao justificar que alguns povos estariam destinados ao trabalho duro e forçado por nascerem mais fortes, enquanto outros, mais débeis e capacitados intelectualmente, deveriam exercer o governo e dominação sobre os primeiros (SANT'ANA, 2005). Tal idéia, segundo Sant'Ana (2005), foi utilizada a partir do século XV para justificar a escravidão de povos menos desenvolvidos tecnicamente. Iniciava-se, a partir disto, o que denominei de distorção histórica.

Nesse contexto, engendrou-se o conceito de raça em termos biológicos, responsável pelo nascimento do racismo moderno, segundo o qual sobretudo negros e indígenas eram considerados inferiores em relação aos brancos. West (2002) aponta a existência de duas fases específicas no racismo moderno. A primeira é concernente ao papel da estética clássica e de normas culturais na legitimação da supremacia branca. A segunda fase ocorre por desdobramentos da antropologia, valorizando-se aspectos estéticos para se defender a imperioridade branca. Segundo o mesmo autor, o Iluminismo ajudou a legitimar essas idéias.

Segundo Miles (1993), na língua inglesa, o termo raça remonta o século XVII, sendo bastante utilizado no século seguinte para explicar e nomear diferenças fenotípicas. A idéia vigorante era de que, na população mundial, haveria raças distintas, cada qual exibindo uma capacidade biológica determinada para o desenvolvimento cultural. Mas foi nos fins do século XIX e início do século XX que o racismo ganhou imensa força, sobretudo na Europa. Segundo Leite (1976), houve duas razões para que isso acontecesse:

Em primeiro lugar, era a fórmula preciosa para justificar o domínio branco sobre o resto do mundo: se as outras raças eram biologicamente inferiores, se eram incapazes de atingir os valores mais elevados da civilização, só poderiam sobreviver como as massas trabalha- 
Francisco Jr., W. E.

doras submetidas aos brancos. Essa justificativa era mais sutil do que parece à primeira vista: através dela o europeu não chegava a sentir conflito ideológico com seus ideais democráticos e liberais. Não fora ele, europeu, que intencionalmente estabelecera as diferenças entre raças; ao contrário, estas eram determinadas pela natureza. Em segundo lugar, o racismo parecia justificado pela teoria evolucionista de Darwin e também sob este aspecto se harmonizava com a vida intelectual européia: se o homem resultara de uma longa evolução, na qual sobreviveram os mais capazes, as várias raças estariam em estágios diferentes de evolução e as menos capazes deveriam ser destruídas pelas mais aptas. (LEITE, 1976, p. 27-8)

De tal maneira, quando os europeus encontravam civilizações nas quais o modo de vida diferia do seu, tentavam moldá-las ao padrão europeu, ou pior, dizimavam muitas delas. Isso colabora com o fato de a raça ser uma construção ideológica e não somente social, uma vez que só existe dentro de uma estrutura de interesse (MARTINS, 2005). No entanto, com o avanço da Biologia, chegou-se ao consenso de que os seres humanos não apresentam significativas diferenças no código genético, independente das características físicas e/ou culturais.

Calcados nessa perspectiva biológica de não existência de raças humanas, alguns autores vêm desenvolvendo o abandono do termo raça (MARTINS, 2005). Defendem a assunção do termo etnia para diferenciar a origem dos povos. A meu ver, para distinções de cunho estritamente cultural e físico, o conceito de etnia é mais pertinente. Entretanto, a relevância de toda a construção histórico-social do termo raça impede o abandono do mesmo. Portanto, abandonar o termo raça poderia implicar negação da relação de poder e dominação de determinadas culturas e povos sobre outros, base na qual se construiu o termo raça. De acordo com Gomes:

Não podemos negar que, na construção das sociedades, na forma como negros e brancos são vistos e tratados no Brasil, a raça tem uma operacionalidade na cultura e na vida social. Se ela não tivesse esse peso, as particularidades e características físicas não seriam usadas por nós, para identificar quem é negro e quem é branco no Brasil. E mais, não seriam usadas para discriminar e negar direitos e oportunidades aos negros em nosso país. (GOMES, 2005, p. 48)

Outros estudiosos ainda cunharam o termo raça social (MARTINS, 2005), justamente para limitar o sentido social das raças. Todavia, não me aprofundarei nessa discussão. O que deve ficar em relevo neste momento é a distinção do sentido biológico, engendrado em séculos anteriores, do sentido atual do termo raça, calcado, sobretudo, na construção histórico-social a qual, sob meu ponto de vista, impede seu abandono.

Portanto, está mais que óbvio que o termo raça, no sentido estritamente biológico de seu significado, é inconcebível para diferenciar seres humanos, uma vez que todos pertencemos a uma mesma raça. Outrossim, não se pode desconsiderar a construção histórico-social do termo. 


\title{
Racismo, preconceito, discriminação e estereótipos: em busca de definições
}

Racismo, preconceito, discriminação e estereótipos são termos crescentemente propalados e cujas idéias não podem ser prescindidas para que possamos entender os fenômenos ao nosso redor. Recentemente, tem havido a preocupação em delinear esses conceitos e, como alerta Silva Jr. (2000, apud THEODORO, JACCOUD, 2005, p. 112), idéia com a qual concordo:

\begin{abstract}
Tratar como sinônimos os termos preconceito e discriminação pode implicar não apenas uma perigosa e totalitária devassa na esfera da liberdade individual, como também - o que é mais freqüente e perverso - na omissão estatal pura e simples face da discriminação, motivada, entre outras razões, pela indefinição dos limites, do papel e dos instrumentos estatais destinados ao enfrentamento da desigualdade e à promoção da igualdade.
\end{abstract}

Sendo assim, é imperioso analisar e diferenciar alguns conceitos fundamentais pelos quais perpassam e se perpetuam fenômenos sociais de interesse no presente texto. Em nossa acepção, sob o ponto de vista da discussão étnico-racial, o racismo é o conceito mais amplo, abarcando as idéias de preconceito, discriminação e estereótipos. Obviamente, existem outros tipos de preconceitos, discriminações e estereótipos que não somente o racial, dentre eles podem ser citadas as questões de gênero, classe social, opção sexual etc. Quando se trata destas outras formas de preconceitos, discriminações e estereótipos, estas não são, obviamente, subordinadas ao racismo.

O racismo, cuja origem remonta o conceito de raça do século XV, é uma construção histórica, social e cultural, fruto de um longo processo ideológico que foi se arraigando aos poucos. De acordo com o Programa Nacional de Direitos Humanos: "Racismo é uma ideologia que postula a existência de hierarquia entre os grupos humanos" (BRASIL, 1998a, p. 12).

Beato (1998, apud SANT'ANA, 2005, p. 60), conceitua o racismo como: "A teoria ou idéia de que existe uma relação de causa e efeito entre as características físicas herdadas por uma pessoa e certos traços de sua personalidade, inteligência ou cultura. E, somados a isso, a noção de que certas raças são naturalmente inferiores ou superiores a outras".

Portanto, no presente contexto, o racismo pode ser compreendido como um fenômeno histórico-social ideológico, consolidado e manifestado por meio de preconceitos, discriminação e estereótipos. Leva-se em conta, também, a questão geográfica e política, pontos importantes para a origem de tal fenômeno social.

O preconceito é uma idéia que precede a própria relação. Como descreve Sant'Ana (2005, p. 62): "preconceito é uma opinião preestabelecida, que é imposta pelo meio, época e educação [...]. Ele pode ser definido também, como indisposição, um julgamento prévio, negativo, que se faz de pessoas estigmatizadas por estereótipos."

Dessa forma, o preconceito torna-se um julgamento prévio, inculcado no dia-a-dia por meio de estigmas e estereótipos. O preconceito se expressa por meio de valores, idéias ou pensamentos pré-moldados. Por isso, é de ordem subjetiva, residindo na consciência e afetivi- 
Francisco Jr., W. E.

dade dos indivíduos. Por si só não fere nenhum direito. Porém, dissemina-se de tal forma que se torna arraigado na sociedade, transformando-se em posições e ações, o que nos remete ao conceito de discriminação.

A discriminação pode ser entendida como "ação de exclusão, restrição ou preferência que impede o tratamento ou acesso igualitário a direitos e oportunidades em função da cor" (THEODORO, JACCOUD, 2005, p. 111-2).

Para Sant'ana, a discriminação é

a conduta (ação ou omissão) que viola direitos das pessoas com base em critérios injustificados e injustos, tais como raça, o sexo, a idade, a opção religiosa e outros. A discriminação é algo assim como a tradução prática, a exteriorização, a manifestação, a materialização do racismo, do preconceito e do estereótipo. (SANT'ANA, 2005, p. 63)

Por sua vez, o estereótipo é uma idéia próxima do preconceito. Na verdade, é o exercício do preconceito, sua exteriorização na forma de palavras e/ou imagens que generalizam opiniões sustentadas pela falta de espírito crítico. Segundo Sant’ana, o estereótipo é manifestação comportamental do preconceito visando "(1) justificar uma suposta inferioridade; (2) justificar a manutenção do status quo; e legitimar, aceitar e justificar: a dependência, a subordinação e a desigualdade" (SANT'ANA, 2005, p. 65).

\section{Existe racismo no Brasil?}

Sem dúvida, o mito da democracia racial ainda aparece inconcusso em boa parte da sociedade brasileira. Tal idéia, desenvolvida no início do século XX, com a miscigenação do povo brasileiro, aporta que a população vive em harmonia, inexistindo atos discriminatórios. Todavia, não é isso o que revelam alguns dados.

Theodoro e Jaccoud (2005), analisando dados do Instituto Brasileiro de Geografia e Estatística (IBGE, 2001), apontam importantes números em relação à diferença socioeconômica entre a população branca e a população negra. Quanto à renda, enquanto a média per capita da população branca era de $R \$ 481,60$, para a população negra a média era de $R$ \$ 205,40. Além disso, dos cerca de 24 milhões de brasileiros localizados abaixo da "linha de indigência", quase $70 \%$ deles eram negros. Colaborando com esses dados de desigualdades, a população que constituía as favelas brasileiras era composta por $6,1 \%$ de negros e 3,0\% de brancos.

Segundo tais indicadores, a condição social da população negra é significativamente inferior à condição da população branca. Para alguns, tal quadro de desigualdades pode ser revertido por meio da melhora dos níveis de educação, o que possibilitaria uma ascensão social dos mais desfavorecidos. A equalização social via universalização do acesso à educação é um dos pressupostos das políticas universalistas. No entanto, caso analisemos comparativamente o acesso à educação entre brancos e negros, as desigualdades também se perpetuam.

A média de anos de estudo, no período de 1900 a 1965, mostra, em todo o período, uma superioridade de cerca de dois anos da população branca em relação à negra. Segundo 
Theodoro e Jaccoud (2005), enquanto 60\% dos estudantes brancos na faixa etária de 15 a 17 anos cursavam o Ensino Médio, apenas 32\% dos estudantes negros da mesma faixa etária estavam no Ensino Médio. Além disso, 84\% dos jovens negros de 18 a 23 anos de idade não haviam completado o Ensino Médio, contra $63 \%$ dos jovens brancos. O analfabetismo, em 2001, atingia 18,2\% da população negra com mais de 15 anos, enquanto o analfabetismo da população branca era de menos da metade, 7,7\%. Quanto ao Ensino Superior, os dados são ainda mais discrepantes. $\mathrm{Na}$ faixa de 20 a 24 anos, 53,6\% de estudantes brancos encontravamse na universidade. Já, para os negros, esse número correspondia a 15,8\%.

Embora concorde que a pobreza não distingue gênero, cor de pele ou idade, é inegável que a distorção histórica pela qual passaram os negros se reflete até os dias atuais. Outrossim, a reprodução dessa distorção histórica manifestada, sobretudo pelo racismo, obstaculiza a ascensão social e econômica da população afrodescendente. Dessa maneira, apenas políticas de cunho universalista não modificarão tão logo tais desigualdades. É neste sentido que emergem as ações afirmativas (SANTOS, 2005), pois a espera paciente de que esta opressão cesse por si não modificará com presteza as estruturas. Por isso, concordo com Paulo Freire quando este defende um combate ao "imobilismo subjetivista que transformasse o ter consciência da opressão numa espera paciente de que um dia a opressão desapareceria por si mesma" (FREIRE, 2005, p. 40-1). Diante de tais apontamentos é que insurge o papel da escola e de seus profissionais.

\section{A escola}

O papel da escola nos dias atuais é um assunto controverso e exaustivamente debatido. Ainda assim, o que se observa, na prática, é um dissenso tamanho, onde cada qual parece pôr em prática o que lhe convém. Para uma corrente de pensadores, o objetivo básico e primordial da escola é a preparação dos alunos para serem incorporados no mercado de trabalho. Tal ideologia permeou a educação brasileira sobretudo nos anos 70, dando propulsão a um imenso número de escolas técnicas. Uma segunda função da escola é a formação de cidadãos críticos para intervenção no mundo. Essa é a proposta presente nos Parâmetros Curriculares Nacionais (PCN) (BRASIL, 1998b). No entanto, é conhecido que grande parte das escolas, sobretudo as privadas, se preocupa realmente com o número de aprovações nos exames vestibulares.

Devido a tamanha disparidade de exigências, a escola aceita, assume e consolida as desigualdades existentes na sociedade, sejam elas de ordem social, cultural ou étnico-racial. Assumindo-se a idéia de que a escola é igual para todos, implicitamente se assume também que cada indivíduo chega onde sua capacidade e esforço pessoal lhe permitem, sendo ignorados os pontos cruciais de desigualdades impostos pela sociedade.

Dessa forma aceitam-se as características de uma sociedade desigual e discriminatória, pois aparecem como o resultado natural e inevitável das diferenças individuais evidenciadas em capacidades e esforços. A ênfase no individualismo, na promoção da autonomia individual, no respeito à liberdade de cada um para conseguir, mediante a concorrên- 
Francisco Jr., W. E.

cia com os demais, o máximo de suas possibilidades, justifica as desigualdades de resultados, de aquisições e, portanto, a divisão de trabalho e a configuração hierárquica das relações sociais [...]. Este processo vai minando progressivamente as possibilidades dos mais desfavorecidos social e economicamente em particular num meio que estimula a competitividade, em detrimento da solidariedade, desde os primeiros momentos da aprendizagem escolar [...]. Assim, a escola legitima a ordem existente e se converte em válvula de escape das contradições sociais e desajustes sociais. (PÉREZ-GÓMES, 1998, p. 16)

Diante de tal panorama contraditório, no qual as demandas da escola parecem inatingíveis na sua completude, é que deve permear também a educação anti-racista, uma vez que não problematizar o racismo na escola é reproduzir a sociedade discriminatória.

Em estudo realizado na região metropolitana de São Paulo, Santos (2001) relata que os educadores: (i) mesmo identificando visões estereotipadas de negros e mulheres em livros, continuavam a utilizar tais materiais sem leitura crítica; (ii) possuíam menor expectativa quanto à capacidade de alunos negros; (iii) atribuíam o problema da discriminação à família e aos próprios negros, por se conformarem com a exclusão e não lutarem por seus espaços. Visão similar não é incomum na maior parte das escolas brasileiras.

Em um belíssimo trabalho, Cavalleiro (2005) pesquisou três escolas públicas de Ensino Fundamental também na cidade de São Paulo. Tal estudo envolveu professores, coordenadores pedagógicos, diretores, funcionários operacionais, alunos e familiares. O estudo conclui que os profissionais envolvidos no processo de escolarização apresentam um pensamento no qual:

- A existência de racismo é negada;

- Não se reconhecem os efeitos negativos prejudiciais do racismo para os negros;

- Não se reconhecem aspectos negativos do racismo também para os brancos;

- Não se buscam estratégias para a participação positiva da criança negra, mesmo que se reconheça a existência de atos discriminatórios.

No que tange a esses aspectos, a criança que sofre discriminação não encontra apoio nos profissionais da escola. Em outro estudo de Cavalleiro (2001), agora com alunos de préescola, a autora relata que, mesmo quando uma aluna foi explicitamente discriminada por meio de ofensas verbais, a professora nada fez. Tal atitude sinaliza, para o opressor, que a ação pode ser repetida. Nesse sentido, Freire alerta: "Não é no silêncio que os homens se fazem, mas na palavra, no trabalho, na ação-reflexão" (2005, p. 90).

A escola, embora diante do conflito de objetivos, deve favorecer a discussão e problematização por meio do diálogo e do questionamento das questões raciais. Torna-se um instrumento poderoso na prática educativa anti-racista. De acordo com Santos (2001):

tratar da discriminação racial em ambiente escolar não significa ajudar a criança negra a ser forte para suportar o racismo, como se apenas ela tivesse problema com sua identidade, com sua auto-estima. Faz-se necessário corromper a ordem dos currículos escolares, 
que insistem em apresentar a produção cultural eurocêntrica como único conhecimento científico válido. (SANTOS, 2001, p. 106)

Ao mesmo tempo, Pérez-Gómes (1998, p. 24) alerta que: "a igualdade de oportunidades não é um objetivo ao alcance da escola. O desafio educativo da escola contemporânea é atenuar, em parte, os efeitos da desigualdade e preparar cada indivíduo para lutar e se defender, nas melhores condições possíveis, no cenário social”.

Diante de toda discussão, emerge uma só certeza, não mais prescindir um tema de tamanha relevância. Há a necessidade de se superar a situação opressora. A meu ver, o primeiro e contundente passo é desvelar as diferenças, valorizando-as como forma integradora dos diferentes povos, nações e grupos sociais, com direitos iguais de acesso aos bens e serviços de que a sociedade dispõe. Para tanto, alguns pontos importantes devem ser levados em consideração na educação, que tenha, também, como um dos pilares sustentadores o combate ao racismo. Com apoio em algumas idéias de Cavalleiro (2001), listam-se, a seguir, algumas questões que devem perpassar uma educação anti-racista:

- Reconhecer a existência do problema racial na sociedade brasileira;

- Buscar permanentemente a reflexão sobre o racismo na escola e na sociedade;

- Não conceber qualquer manifestação de preconceito ou discriminação e cuidar para que as relações interpessoais sejam respeitosas;

- Considerar a diversidade presente no ambiente escolar e utilizá-la como forma integradora, encorajando a participação de todos;

- Fazer uma leitura crítica da História Brasileira, mediante a qual seja possível mostrar a contribuição de diferentes grupos na construção de nosso país;

- Buscar materiais que contemplem a diversidade cultural e étnico-racial, bem como aspectos da África que auxiliem a construção de um currículo menos etnocêntrico;

- Pensar meios e formas em que a educação contribua para o reconhecimento e valorização da diversidade cultural e étnico-racial brasileira;

- Elaborar ações que propiciem o fortalecimento da identidade e auto-estima de educandos pertencentes a grupos discriminados.

\section{O ensino de Ciências: quais contribuições são possíveis?}

$\mathrm{Na}$ maioria das vezes, quando falamos em Ciência, é totalmente desconsiderada a dimensão de Ciência e tecnologia dos povos pré-colombianos, africanos, indígenas etc. A supervalorização de determinadas culturas, por exemplo, a européia, em detrimento de outras, é um ato discriminatório e que, amiúde, nos passa despercebido. Deste modo, a leitura da Ciência que conhecemos como moderna implica a leitura de uma Ciência européia, branca, cristã e masculina, sendo um tanto reducionista e discriminatória, como também descreve Chassot (2003). Não diferente, a Ciência ensinada na escola carreia as características acima descritas. Por exemplo, quando tratamos os alquimistas como precursores da Química, a idéia que se tem é que estes viviam somente na Europa. Ademais, desconsideramos, por exemplo, o conhecimento químico utilizado no Egito Antigo para embalsamar os corpos dos faraós 
Francisco Jr., W. E.

egípcios, os quais se mantiveram preservados durante séculos. Por isto a necessidade de uma releitura desta Ciência.

Não obstante, é salutar uma ressalva quando se abordarem tais questões. O discurso do professor não deve sublinhar de forma adversativa a Ciência e tecnologia dos povos africanos; por outro lado, deve demonstrar que tais povos possuíam conhecimentos científicos, por vezes bem avançados. No campo da metalurgia, habitantes de uma região onde hoje é a Tanzânia produziam aço em fornos que atingiam temperaturas $200^{\circ} \mathrm{C} \mathrm{a} 400^{\circ} \mathrm{C}$ superiores aos fornos europeus até o século XIX (NASCIMENTO, 2001). Tal tecnologia de fundição e produção de aço é bastante utilizada atualmente, e envolve conhecimentos físico-químicos acerca das propriedades periódicas de elementos.

Registros de 1879, de um cirurgião inglês, numa região que hoje compreende a Uganda, mostram uma cesariana realizada, o que demonstra a necessidade de conhecimentos sobre conceitos e técnicas de assepsia, anestesia, cauterização etc. Há cerca de cinco ou sete séculos, povos habitantes da região de Mali já conheciam o Sistema Solar, a Via Láctea e os anéis de Saturno, o que nos faz pensar no adjetivo de moderna dado à Ciência européia após a revolução copernicana, mediante a qual se iniciou a migração do geocentrismo para o heliocentrismo.

Os egípcios desenvolveram balanças com o uso de pesos, o que nos remete a conceitos físicos de equilíbrio de corpos. Papiros egípcios descobertos no final do século XIX demonstraram relatos pelos quais são descritas receitas de pomadas e colírios, o que requereria conhecimentos de preparo de soluções e solubilidade. A construção das pirâmides exigiu conhecimento físico para transportar enormes pedras até pontos altos por meio de planos inclinados. A pirâmide de Quéops tem, por exemplo, mais de 23 milhões de blocos de pedras calcárias que chegam a pesar 2,5 toneladas cada. O conhecimento matemático e aritmético dos egípcios também era evoluído, permitindo o desenvolvimento da agrimensura e de um sistema de irrigação que aproveitara os períodos de cheia. Também foram capazes de identificar o valor de $\pi$ com grande exatidão, e calcular ângulos à precisão de $0,07^{\circ}$ (NASCIMENTO, 2001).

Introduzir o tema do racismo nas aulas, porém, não é algo fácil. Primeiramente, o professor deve estar convicto de suas posições e bem fundamentado teoricamente sobre a origem do problema, suas conseqüências e dados estatísticos das desigualdades sociais. Nessa discussão, o diálogo horizontal deve prevalecer sempre. Ao mesmo tempo, o professor, de forma alguma, deve conceber atitudes discriminatórias, além de possuir sensibilidade para reconhecer e analisar criticamente episódios de discriminação. As questões descritas por Cavalleiro (2001) configuram os passos importantes para associar o racismo ao ensino de Ciências. O primeiro momento é abalar o mito da democracia racial no Brasil (FRANCISCO JR., 2007). Nesse sentido, tentarei apresentar algumas sugestões para a discussão.

Todavia, o caminho é longo, haja vista a escassez de informações. Existem poucos dados sobre os conhecimentos forjados na África, justamente pela supervalorização do conhecimento europeu. Mas uma indagação que não fenece recai, exatamente, sobre a dificuldade em se encontrarem tais informações. Será que esses povos não desenvolveram conhecimentos? Ou será que seus conhecimentos foram praticamente aniquilados durante a colonização? Uma vez que a transmissão desses conhecimentos ocorria, geralmente, pela oralidade, o extermínio de povos e tribos teve conseqüências desastrosas. Algo similar ao que ocorreu e ocorre no Brasil com as tribos indígenas. Por isso, a impressão que se tem é de que tais povos não desenvolve- 
ram conhecimento algum. É essa leitura crítica que deve perpassar o ensino de Ciências. O primeiro desafio é fazer com que nós, professores de Ciências, reconheçamos o problema.

Após isso, uma primeira sugestão é procurar situações e/ou temas que envolvam conhecimentos científicos e participação de povos africanos ou seus descendentes, discutindo as implicações desses conhecimentos no cenário social, econômico e político, tanto na época passada como na presente. Por exemplo, a produção de açúcar no período colonial foi movida por negros escravizados em condições subumanas. Entretanto, isso parece naturalizado na sociedade e não causa nenhum tipo de choque nas pessoas. O que aconteceu e como viviam esses negros escravizados? Quem lucrava com a produção de açúcar? O que o Brasil e sua economia ganhavam e perdiam com isso? Qual era o interesse em se empregarem negros como trabalhadores forçados? Por que não eram utilizados os brancos para esse tipo de trabalho? Qual o legado dessa época no tocante à economia brasileira? O que mudou na forma de plantio e cultivo da cana, bem como da produção de açúcar? Trata-se de uma discussão política acompanhada da discussão dos conceitos científicos da produção de açúcar.

Existem outros temas. No caso da Biologia, por exemplo, quando da discussão de conceitos relacionados à higiene, doenças infecciosas, sistema nervoso e outros afins, por que não apresentar que, em uma região hoje compreendida pela Uganda, haviam se desenvolvido técnicas de assepsia e anestesia que possibilitaram cirurgias cesarianas? Enquanto, no Brasil, ainda há casos de óbito por falta de assepsia ou por infecções, inclusive dentro de hospitais. Tais apontamentos vão valorizando, aos poucos, outras culturas.

No caso da Química e da Física, pode ser discutido como os habitantes da Tanzânia desenvolveram fornos que alcançavam temperaturas bem mais elevadas que os fornos europeus até o século XIX. Os fornos foram importantes na produção de potes cerâmicos, ligas metálicas e vidros, materiais que constituem boa parte da História da Humanidade. Além disso, os fornos são fundamentais até hoje. Conceitos físicos de termologia e conceitos químicos acerca dos aspectos energéticos e cinéticos das reações podem ser explorados a partir disso. Ademais, o que aconteceu com esse conhecimento? Por que essas informações não aparecem na imprensa? São essas discussões que devem ser introduzidas conjuntamente ao estudo dos conhecimentos disciplinares.

Outra questão interessante é a respeito da produção de bolas de bilhar, que, até 1800, era realizada com marfim. Contudo, qual a origem desse marfim? Quem jogava bilhar nessa época? Os colonizadores tinham direito a esse marfim? E quanto aos povos dessas regiões, quais problemas foram acarretados a eles? A análise da constituição e das propriedades do marfim pode fomentar estudos sobre propriedades físico-químicas dos materiais, ligações químicas, dentre outros. Conceitos como colisões de corpos e conservação de energia podem ser estudados pela Física, com base na discussão do jogo de bilhar. Além disso, o problema de exploração de bens naturais pode ser explorado. Isso ocorre, em outras instâncias, até hoje. Por exemplo: de onde vêm e quem usa os casacos de peles de animais? Animais, em sua maioria, originários da África. À medida que indagações simples forem discutidas, os estudantes criarão e fortalecerão um espírito crítico cada vez maior, sendo capazes de analisar, também criticamente, outras situações anteriormente despercebidas, não somente em relação ao racismo.

$\mathrm{Na}$ realidade, não há uma receita para se trabalhar esses conhecimentos em sala de aula. Porém, acredito que importantes discussões possam ser empreendidas com base em 
situações e/ou dados históricos. De tal maneira, nós, professores, devemos buscar, na História da Ciência e na História Africana, episódios ou práticas sociais e/ou científicas passíveis de serem explorados em sala de aula, obviamente não prescindidos do conteúdo curricular. Não é difícil perceber que, para isso ocorrer, faz-se necessária uma reorientação curricular. Contudo, enquanto isso não acontece, não podemos ser complacentes com essa questão. Episódios históricos ou práticas sociais e/ou científicas podem ser escolhidos para se concatenarem ao conteúdo curricular.

Além das sugestões de temas aqui apresentadas, outros podem ser pesquisados em livros específicos sobre a História da Ciência, como o de Bernal (1968), e sobre a História Africana (NASCIMENTO, 1996; HERNANDEZ, 2005). A aproximação entre professores de Ciências e especialistas em História Africana também pode ser uma forma de complementar a atuação em sala de aula.

Esses são apenas alguns dos exemplos em que o ensino de Ciências pode contribuir para romper com uma visão eurocêntrica de Ciência. Essa é uma forma de valorizar a diversidade cultural e étnico-racial na construção do conhecimento da Humanidade. Assim, podese ir rumo a um currículo menos etnocêntrico.

\section{Contribuições de alguns pensadores da educação sobre o racismo}

\section{Abordagens humanistas (sociológicas)}

\section{Celestin Freinet}

Freinet foi crítico da escola tradicional, sobretudo em relação a seu autoritarismo. Autoritarismo similar ao que foi empregado pelos povos europeus ao elevarem o status do que lhes era específico para se reconhecerem como superiores e dominarem outros povos e espaços geográficos.

Ataco no entanto aqueles que, por sua própria autoridade, se declararam montanha para gerar e orientar a torrente, para dominar o vale; aqueles que julgam ter descoberto os cumes, mas que esquecem que esses cumes não existiriam sem os flancos dos vales que os erguem para as nuvens [...]. (FREINET, 1969, p. 66)

Como assume o indivíduo como membro de uma coletividade, é intrínseca a idéia de uma educação popular que busque mudar a estrutura social vigente, balizada por seus ideais marxistas. Para Freinet, a educação não deve prescindir do papel social e humanizador, ao mesmo tempo em que não pode ignorar a vivência das pessoas, o contato com o mundo. Dentro dessa perspectiva, as idéias de Freinet ajudam a pensar uma educação menos etnocêntrica, quando aponta a:

Necessidade [...] de ligar a ciência de hoje à tradição do passado e às lições do presente, naquilo que elas têm de lógico, de racional e de vivo. É igualmente necessário ligar o ensino metódico da escola a essa 
cultura difusa pela qual o meio marca para sempre o corpo e as almas. E ligá-las não artificialmente, mas tão intimamente, tão naturalmente que um seja a seqüência normal e o complemento da outra. (FREINET, 1969, p. 85)

Dessa maneira, Freinet retrata um movimento dialético entre escola e cultura, ressaltando não um multi ou pluriculturalismo, mas um interculturalismo, verificado quando o autor fala em "ligar o ensino metódico da escola a essa cultura difusa pela qual o meio marca para sempre o corpo e as almas". Ao mesmo tempo, Freinet entende que:

Os educadores, mais do quaisquer outros, devem empenhar-se primeiro em ver com justeza, e depois em fazer surgir nem que seja um vislumbre de verdade. Então, mesmo que não triunfem plenamente, enquanto os seus olhos forem guiados por esse clarão, cumprirão uma missão superior. (FREINET, 1969, p. 87)

Embora a contribuição de Freinet seja notória para se pensar uma educação mediante a qual se possa romper com qualquer forma de desigualdade, há de se levar em consideração as bases marxistas de seu pensamento, uma vez que as relações raciais não se incluem simplesmente na categoria de classes, mas se configuram como uma categoria à parte.

\section{Paulo Freire}

Paulo Freire é um dos autores que contribui mais e melhor para se pensar uma educação anti-racista. Em seu pensamento, Freire preconiza os homens como seres inacabados e que se educam em comunhão por meio do diálogo. Isto faz surgir um novo termo:

Não mais educador do educando, não mais educando do educador, mas educador-educando com educando-educador. Desta maneira, o educador já não é o que apenas educa, mas o que, enquanto educa, é educado, em diálogo com o educando que, ao ser educado também educa. (FREIRE, 2005, p. 78-9)

Deste modo, o ensinar sempre preconiza o aprender, e vice-versa, sendo ambos, educador e educando, sujeitos do processo. Defendendo que a educação seja concebida com base na realidade do educando, isto é, por meio de algo que faça sentido ao educando, e permita, deste modo, uma forma de intervenção no mundo e transformação da realidade, Freire pondera tal realidade como experiência histórica, existencial, no mundo e com o mundo, pois, estar no mundo implica necessariamente estar com o mundo e com os outros, de tal modo que os homens em comunicação e intercomunicação "vão se percebendo, criticamente, como estão sendo no mundo com que e em que se acham" (FREIRE, 2005, p. 82). Não há como eliminar a historicidade do mundo, a realidade é o contexto histórico, social e cultural na qual os seres humanos interferem por meio de uma relação inexoravelmente dialética.

No bojo de tais idéias, é inconcebível qualquer prática preconceituosa e/ou discriminatória, pois isto fere princípios básicos preconizados por Paulo Freire, como: a fé nos seres 
Francisco Jr., W. E.

humanos, a luta pela igualdade, a humildade, a ética, a autonomia, o bom senso. Além disso, a educação, partindo da realidade do educando, admite a não superioridade de determinada cultura em relação a outra. Logo, a presença da diversidade cultural na sala de aula deve ser respeitada e debatida, uma vez que faz parte da vida de todos que estão ali presentes.

A questão da identidade cultural, de que fazem parte a dimensão individual e a de classe dos educandos cujo respeito é absolutamente fundamental na prática educativa progressista, é problema que não pode ser desprezado. Tem que ver com a assunção de nós por nós mesmos. (FREIRE, 2006, p. 41-2)

Ainda nas palavras de Freire: "Uma das tarefas mais importantes da prática educativo-crítica é propiciar as condições em que os educandos em suas relações uns com os outros e todos com o professor ou a professora ensaiam a experiência de assumir-se" (FREIRE, 2006, p. 41).

No contexto do presente trabalho, esse assumir deve ser a assunção do reconhecimento e valorização de culturas diferentes, da necessidade de se superarem atos discriminatórios, do reconhecer-se na condição opressora de discriminador ou oprimida de discriminado, assim como a assunção da vontade de liberta-se. De acordo com Freire: "só através da práxis autêntica que, não sendo "blábláblá", nem ativismo, mas ação e reflexão, é possível fazê-lo." Ainda na visão de Freire (2005, p. 42): "A práxis, porém, é reflexão e ação dos homens sobre o mundo para transformá-lo. Sem ela, é impossível a superação da contradição opressoresoprimidos". Este é um dos grandes desafios de uma educação humanizadora. O conhecimento só é válido se for utilizado como forma de intervenção e transformação da realidade, caso contrário, estaríamos nos conformando com a situação opressora na qual estamos imersos, seja opressão econômica, cultural ou étnico-racial.

Outro saber de que não posso duvidar um momento sequer na minha prática educativo-crítica é o de que, como experiência especificamente humana, a educação é uma forma de intervenção no mundo. Intervenção que além de conhecimento dos conteúdos bem ou mal ensinados e/ ou aprendidos implica tanto o esforço de reprodução da ideologia dominante quanto o seu desmascaramento [...] Neutra, indiferente a qualquer destas hipóteses, a da reprodução da ideologia dominante ou a de sua contestação, a educação jamais foi, é, ou pode ser. É um erro decretá-la como tarefa apenas reprodutora da ideologia dominante como erro é tomá-la como uma força de desocultação da realidade, a atuar livremente, sem obstáculos e duras dificuldades. (FREIRE, 2006, p. 98-9)

Essas idéias convergem ao papel da escola, da estrutura curricular bem como das diferentes disciplinas na educação anti-racista. 


\section{Abordagens cognitivistas}

\section{Robert Gagné}

A teoria de Gagné considera o conhecimento em seqüências lógicas, as quais levam a tipos de aprendizagem que, também, se complexificam. De tal maneira, para realizar uma tarefa mais complexa, o aluno deverá possuir habilidades mais simples, adquiridas anteriormente, denominadas de pré-requisitos, as quais possam ajudá-lo a concluir tal tarefa.

Assim, acompanhar uma seqüência previamente planejada e, dessa maneira, evitar a omissão de habilidades necessárias como requisitos prévios em qualquer caminho que conduza à aprendizagem parece ser um processo de grande importância que deve ser adotado para se alcançar eficiência no ensino. (GAGNÉ, 1971, p. 156)

Por isso, Gagné defende a esquematização de uma seqüência de ensino, para que não se prescindam de etapas fundamentais na aquisição de conteúdos relativos a determinado campo de conhecimento. De tal maneira: "Antes de empreendermos qualquer tipo de aprendizagem, devemos esboçar um plano de acordo com seu conteúdo" (GAGNÉ, 1971, p. 156).

Gagné também ressalta que "há vários caminhos disponíveis, alguns tão bons quanto outros, no sentido de atingir o objetivo desejado. Mas o que não é possível em tal plano é "passar por cima" de algumas habilidades intermediárias essenciais" (GAGNÉ, 1971, p. 156).

Uma vez que, de acordo com Gagné, qualquer pessoa que percorra esse caminho lógico é capaz de aprender, caso isso não ocorra, é porque alguma habilidade intermediária não foi alcançada. Nesse contexto, o papel do professor é organizar o ambiente de aprendizagem (seqüência e meios de ensino), o que dará estimulação ao aluno. Todavia, a teoria de Gagné desconsidera aspectos sociais e culturais dos alunos, os quais influem notadamente na aprendizagem. A grande questão é: Será que toda vez que um aluno não atinge algum objetivo de aprendizagem, isto se estabelece exclusivamente por alguma habilidade não adquirida? Ou, reformulando: quais fatores influenciam a não assunção de determinados conteúdos durante a seqüência?

Indo mais além, qual a diferença entre alunos brancos e negros que fazem estes últimos terem um índice de evasão e repetência escolar bem mais elevado? A teoria de Gagné limita o pensamento de tal questão justamente por desconsiderar questões de classe, gênero, étnico-raciais etc. De acordo com Munanga (2005):

Não precisamos ser profetas para compreender que o preconceito incutido na cabeça do professor e sua incapacidade de lidar profissionalmente com a diversidade, somando-se ao conteúdo preconceituoso dos livros e materiais didáticos e às relações preconceituosas entre alunos de diferentes ascendências étnico-raciais, sociais e outras, desestimulam o aluno negro e prejudicam seu aprendizado. O que explica o coeficiente de repetência e evasão escolar altamente elevado do alunado negro, comparativamente ao do alunado branco. (MUNANGA, 2005, p. 16) 
Portanto, com base no pensamento de Gagné, a aprendizagem pode não ocorrer porque, em algum momento da seqüência de conteúdo, o ambiente não é estimulante suficiente para superar o racismo do ambiente escolar. Isto não exime o papel do professor, como destacado acima por Munanga (2005), que, na organização da seqüência de conteúdo, deve levar em conta questões étnico-raciais, culturais, sociais etc.

\section{Vygotsky}

Vygotsky faz relação entre a elaboração do pensamento e da linguagem, defendendo a realização do pensamento na palavra e a aprendizagem como transformação da linguagem em pensamento, sendo tal linguagem social.

Todas as funções psicointelectuais superiores aparecem duas vezes no decurso do desenvolvimento da criança: a primeira vez, nas atividades coletivas, nas atividades sociais, ou seja, como funções interpsíquicas; a segunda, nas atividades individuais, como propriedades internas do pensamento da criança, ou seja, como funções intrapsíquicas. $\mathrm{O}$ desenvolvimento da linguagem serve como paradigma de todo o problema examinado. A linguagem origina-se em primeiro lugar como meio de comunicação entre a criança e as pessoas que a rodeiam. Só depois, convertido em linguagem interna, transforma-se em função mental interna que fornece os meios fundamentais ao pensamento da criança. (VYGOTSKY, 1988, p. 114)

Vygotsky aponta, por meio de sua teoria, que os processos psicológicos se relacionam com o ambiente social e cultural, sendo a linguagem de extrema relevância para a transmissão da cultura dos povos. Embora Vygotsky sublinhe a conexão entre fatores sociais, culturais, históricos e pessoais, ao mesmo tempo, eleva os conceitos validados cientificamente a "conceitos verdadeiros". A meu ver, tal proposição implica, de início - mesmo que isto não esteja explicitado nas obras do autor - uma visão etnocêntrica e preconceituosa, uma vez que os "conceitos verdadeiros" que Vygotsky aborda são cunhados na Europa, branca, cristã e masculina. Não vejo como levar para a sala de aula aspectos culturais e sociais, elevando alguns tipos de conhecimentos em detrimento de outros, cujos valores e relevância podem estar em patamares equivalentes aos primeiros. Portanto, é difícil pensar uma educação que leve em conta e valorize as diferenças, uma vez que o pensamento de Vygotsky torna-se etnocêntrico por preconizar a existência de alguns valores superiores.

\section{Jean Piaget}

Piaget, assim como os outros pensadores cognitivistas acima discutidos, não contribui efetivamente para se pensar uma educação anti-racista. Sua teoria é mais direcionada ao entendimento do pensamento e do desenvolvimento cognitivo da criança. Preconiza que o desenvolvimento precede a aprendizagem. Para Piaget, o desenvolvimento "é uma equilibração progressiva, uma passagem contínua de um estado de menor equilíbrio para um estado de equilíbrio superior" (PIAGET, 1964, p. 11). Segundo Piaget (1964), todo conhecimento se 
origina na ação, e tal conhecimento só é possível quando sujeito e objeto relacionam-se, de modo que o sujeito age sobre o objeto.

Embora valorize o conhecimento cientifico, não vejo, na obra de Piaget, ao menos de modo explícito, o conhecimento científico referendado com o verdadeiro conhecimento. De tal modo, ainda que Piaget não contribua na questão do racismo, não vejo, em suas idéias, proposições explicitamente etnocêntricas, tais quais as observadas em Vygotsky, e que são uma forma de reproduzir as desigualdades. Piaget enfatiza, sim, a natureza racional, a importância do método, do procedimento experimental para a confiabilidade das pesquisas e, conseqüentemente, validade de suas descobertas. Esse é o caráter científico mais emblemático de suas idéias, imbuído em seus métodos de pesquisa.

\section{David Ausubel}

Um dos pontos mais importantes da teoria ausubeliana converge ao conceito de aprendizagem significativa. De acordo com esta teoria, o fator mais importante é o conhecimento anterior, isto é, aquilo que o aprendiz já sabe. Portanto, a nova informação deve encontrar suporte em idéias já presentes na estrutura cognitiva do aprendiz para que seja incorporada. Ausubel é o único dos autores da psicologia que aborda explicitamente a questão racial, ao admitir que o aluno negro tem, em média, índices de reprovação e evasão escolar maiores, comparados aos dos alunos brancos, devido uma "desvantagem cultural". Como conseqüência, o alunado negro não aprende, pois não possui os conhecimentos prévios necessários.

Para tanto, propõe uma forma de minimizar tal desvantagem. Ao fazer tal delineamento, no entanto, Ausubel considera a diferença como sinônimo de inferioridade, questão já discutida anteriormente. De tal modo, justifica a não aprendizagem por tal "desvantagem cultural", ignorando que os principais motivos são o racismo do ambiente escolar e a condição econômica. Além disso, Ausubel cria estereótipos ao descrever o problema de aprendizagem dos negros no ambiente escolar como fruto do ambiente familiar.

As famílias negras são muito mais instáveis do que as famílias brancas de classe baixa. Os lares desfeitos são bem mais comuns entre famílias negras do que entre famílias brancas. Os pais estão freqüentemente mais ausentes e uma atmosfera familiar matriarcal e negativa comumente prevalece. Dessa forma, as crianças negras de classe baixa são freqüentemente impedidas de alcançar os beneficios da afeição dos pais e da educaşão. Elas são geralmente criadas pela avó ou pela irmã mais velha, enquanto as mais trabalham para sustentar a família abandonada pelo pai. (AUSUBEL, NOVAK, HANESIAN, 1980, p. 406) (grifo nosso)

Isso demonstra uma visão extremamente estereotipada das famílias negras, além de justificar o mau desempenho das crianças negras na escola por tal "desestruturação familiar", o que isentaria o papel da escola e dos profissionais da educação em tal problema. Na verdade, como analisamos aqui, a escola possui responsabilidade em tal problema, uma vez que não atende ainda os requisitos de uma educação anti-racista, reproduzindo e, por vezes, multiplicando as desigualdades da sociedade em seu ambiente. 
Francisco Jr., W. E.

\section{Considerações finais}

O objetivo deste trabalho é chamar a atenção para o tema do racismo, uma vez que o mesmo necessita ser combalido também pelo ensino de Ciências. Não tentei apresentar estratégias de ensino para isso, mas, por outro lado, procurei apontar caminhos de como iniciar a discussão do tema, ao mesmo tempo em que se trabalham os conhecimentos científicos. A idéia é de que professores e pesquisadores possam buscar informações acerca do tema, sobretudo na História da Ciência e da África, para o desenvolvimento, aplicação e análise de materiais. Isso é fundamental e constitui o principal desafio atual da educação antiracista devido à falta de informações. Muito pode/deve ser desenvolvido, sobretudo em termos de materiais didáticos que abordem o pluriculturalismo brasileiro no ensino de Ciências. A tarefa é árdua, mas, por isso mesmo, requer a atenção de professores e pesquisadores em ensino de Ciências.

Por isso, busquei apresentar uma visão inicial pela qual seja possível uma idéia de como o racismo está incutido na sociedade e, também, no ensino de Ciências. Além disso, a breve análise de algumas teorias educacionais demonstra a lacuna existente no que concerne à questão racial, sobretudo quando convergimos às abordagens cognitivistas, pelo fato de estas se preocuparem mais com a natureza individual da aprendizagem. Espero, com este ensaio, que a comunidade de pesquisa em educação em Ciências solidarize-se com a questão e passe a discutir mais efetivamente o tema.

\section{Referências}

AUSUBEL, D. P.; NOVAK, J. D.; HANESIAN, H. Psicologia educacional. 2. ed. Rio de Janeiro: Interamericana, 1980.

BERNAL, J. D. Science in History. Cambridge: MIT Press. Illustrated Edition, 1968. v. 1.

BRASIL. Programa Nacional dos Direitos Humanos. Gênero e raça: todos pela igualdade de oportunidades: teoria e prática. Brasília: MTb-a/Assessoria Internacional, 1998a.

Ministério da Educação e Cultura. Secretaria de Educação Fundamental.

Parâmetros Curriculares Nacionais. Brasília: MEC, 1998b.

CAVALLEIRO, E. Discriminação racial e pluralismo em escolas públicas da cidade de São Paulo. In: SECRETARIA DE EDUCAÇÃO CONTINUADA, ALFABETIZAÇÃO E DIVERSIDADE (SECAD). Educação anti-racista: caminhos abertos pela lei federal $\mathrm{n}^{\circ}$ 10.639/03. Brasília: Ministério da Educação, Secretaria de Educação Continuada, Alfabetização e Diversidade (MEC-SECAD), 2005. p. 65-104.

Educação anti-racista: compromisso indispensável para um mundo melhor. In:

Racismo e anti-racismo na educação: repensando nossa escola. São Paulo: Selo Negro, 2001. p. 141-60. 
Educação anti-racista: reflexões ...

CHASSOT, A. Alfabetização científica: questões e desafios para a educação. 3. ed. Ijuí: Unijuí, 2003.

FRANCISCO JR., W. E. Opressores-oprimidos: um diálogo para além da questão étnicoracial. Química Nova na Escola, São Paulo, n. 26, p. 10-2, 2007.

FREINET, C. Educação pelo trabalho. Lisboa: Presença, 1969. v. 1.

FREIRE, P. Pedagogia da autonomia. 33. ed. Rio de Janeiro: Paz e Terra, 2006.

. Pedagogia do oprimido. 43. ed. Rio de Janeiro: Paz e Terra, 2005.

GAGNÉ, R. M. Como se realiza a aprendizagem. Rio de Janeiro: LTC, 1971.

GOLDBERG, D. T. Modernity, race and morality. In: ESSED, P.; GOLDBERG, D. T. (Orgs.). Race critical theories, text and context. Malden/Oxford: Blackwell Publishers, 2002. p. 283-306.

GOMES, N. L. Alguns termos e conceitos presentes nas relações raciais no Brasil: uma breve discussão. In: SECRETARIA DE EDUCAÇÃO CONTINUADA, ALFABETIZAÇÃO E DIVERSIDADE (SECAD). Educação anti-racista: caminhos abertos pela lei federal no 10.639/03. Brasília: Ministério da Educação, Secretaria de Educação Continuada, Alfabetização e Diversidade (MEC-SECAD), 2005. p. 39-62.

HERNANDEZ, J. D. A África na sala de aula: visita à história contemporânea. São Paulo: Selo Negro, 2005.

IANNI, O. A era da globalismo. Rio de Janeiro: Civilização Brasileira, 1997.

LEITE, D. M. O caráter nacional brasileiro: história de uma ideologia. 3. ed. Pioneira: São Paulo, 1976.

MARTINS, A. R. N. Racismo e imprensa - argumentação no discurso sobre as cotas para negros nas universidades. In: SANTOS, I. A. (Org.). Ações afirmativas e combate ao racismo nas Américas. Brasília: Ministério da Educação, Secretaria de Educação Continuada, Alfabetização e Diversidade (MEC-SECAD), 2005. p. 179-207.

MILES, R. Racism after 'race relations'. Londres/Nova Iorque: Routledge, 1993.

MUNANGA, K. Apresentação. In: Superando o racismo na escola. 2. ed. Brasília: MEC-SECAD, 2005. p. 15-20.

NASCIMENTO, E. L. Sanfoka: educação e identidade afrodescendente. In: CAVALLEIRO, E. (Org.). Racismo e anti-racismo na educação: repensando nossa escola. São Paulo: Selo Negro, 2001. p. 115-40.

(Org.). Sankofa: matrizes africanas da cultura brasileira. Rio de Janeiro: EDUERJ, 1996.

PÉREZ-GÓMEZ, A. I. Os processos de ensino e aprendizagem: análise didática das principais teorias de aprendizagem. In: GIMENO SACRISTÁN, J.; PÉREZ-GÓMEZ, A. I. (Orgs.). Compreender e transformar o ensino. 4. ed. Porto Alegre: Artmed, 1998. p. 27-51. 
Francisco Jr., W. E.

PIAGET, J. Seis estudos de psicologia. Rio de Janeiro: Forense Universitária, 1964.

SANT'ANA, A. O. História e conceitos básicos sobre o racismo e seus derivados. In: MUNANGA, K. (Org.). Superando o racismo na escola. 2. ed. Brasília: MEC-SECAD, 2005. p. 39-67.

SANTOS, I. A. A responsabilidade da escola na eliminação do preconceito racial: alguns caminhos. In: CAVALLEIRO, E. (Org.). Racismo e anti-racismo na educação: repensando nossa escola. São Paulo: Selo Negro, 2001. p. 97-113.

SANTOS, S. A. (Org.). Ações afirmativas e combate ao racismo nas Américas. Brasília: Ministério da Educação, Secretaria de Educação Continuada, Alfabetização e Diversidade (MEC-SECAD), 2005.

THEODORO, M.; JACCOUD, L. Raça e educação: os limites das políticas universalistas. In: SANTOS, S. A. (Org.). Ações afirmativas e combate ao racismo nas Américas. Brasília: Ministério da Educação, Secretaria de Educação Continuada, Alfabetização e Diversidade (MEC-SECAD), 2005. p. 103-19.

VYGOTSKY, L. S. Aprendizagem e desenvolvimento intelectual na idade escolar. In: .; LURIA, A. R.; LEONTIEV, A. N. (Orgs.). Linguagem, desenvolvimento e aprendizagem. São Paulo: Edusp, 1988. p. 103-17.

WEST, C. A genealogy of modern racism. In: ESSED, P.; GOLDBERG, D. T. (Orgs.). Race critical theories, text and context. Malden/Oxford: Blackwell Publishers, 2002. p. $90-112$.

Artigo recebido em novembro de 2007 e aprovado em agosto de 2008. 